\title{
Superhydrophobic Asphalt Pavements: Surface Improvement
}

\author{
Iran Rocha Segundo ${ }^{1, *}$, Salmon Landi Jr. ${ }^{2,3}$, Elisabete Freitas $^{1}$, Verônica Castelo Branco ${ }^{4}$, Manuel F. M. Costa ${ }^{2}$, \\ Joaquim Carneiro ${ }^{2}$ \\ ${ }^{1}$ Civil Engineering Department, University of Minho, Azurém Campus, Guimarães, Portugal \\ ${ }^{2}$ Physics Department, University of Minho, Braga \& Guimarães, Portugal \\ ${ }^{3}$ Federal Institute Goiano, Rio Verde - GO, Brazil \\ ${ }^{4}$ Transportation Engineering Department, Federal University of Ceará, Fortaleza, Brazil
}

\begin{abstract}
The most adverse weather condition for road safety happens when there is water, snow, or ice on the road surface because their presence highly decreases friction. Therefore, it is essential to drain or repel them quickly. If the water drops are repelled from the surface or the ice/snow formation is avoided with the application of superhydrophobic coatings, roads become safer. In order to functionalize the asphalt mixtures used in road pavements, nano/micromaterials, such as Polytetrafluoroethylene (PTFE), $\mathrm{TiO}_{2}$, and $\mathrm{SiO}_{2}$, among others have been applied by spraying coating. The mixes are usually characterized by the water contact angle, and the surface roughness is typically assessed by optical and electron analysis. This research work aims to present a brief overview of superhydrophobic asphalt mixtures.
\end{abstract}

\section{Introduction}

The water, snow, and ice over the surface of the road pavements cause time waste, economic loss, polluting the environment and daggering passenger safety, and traffic congestion. Also, due to the presence of ice/snow over airport roads, flights are cancelled, causing personal problems for travellers and millions of losses for the airline companies and airports [1]. The conventional method to melt the ice/snow over the pavement's surface is spreading salt (mainly chloride salts, for example, $\mathrm{NaCl}$ and $\mathrm{CaCl}_{2}$ ) and chemical compounds, which affect the asphalt pavement performance and oxidize vehicles and special structures (i.e., bridges), and, at long-term period, it causes environmental problems [2].

One of the main functional characteristics of road pavements is friction. It expressively reduces when there is water or ice on the road surface. Thus, it is essential to drain or repel the surface water quickly. Superhydrophobic materials can do it fast, and, by their self-cleaning effect, the dirt particles are removed [1,3]. This research work aims to present an overview of superhydrophobic capability applied to asphalt mixtures.

\section{Superhydrophobic Asphalt Mixtures Using Nano/microparticles}

Wetting is the ability of a liquid (mainly water) to maintain contact with a solid surface, resulting from intermolecular interactions. As reported by Wenzel (1936), wettability is described by a thermodynamic process. Regarding the hydrophilic surfaces, the process is spontaneous since the wet interface free energy is inferior to that of the dry interface. Whereas for hydrophobic surfaces, the process is non-spontaneous because the dry interface free energy is lower than that of the wet interface $[1,3,4]$. Furthermore, the wettability is also directly related to the surface roughness. Increases on roughness raise the contact angle (CA) between the (water) drop and the material surface; that is, it can improve the hydrophobicity [4].

The superhydrophobic capability is achieved when the $\mathrm{CA}$ is higher than $150^{\circ}$ [5]. While, according to some authors, CA should be lower than 5 or $10^{\circ}$ to have a superhydrophilic, or super-wettable surface [5].

Superhydrophobic surfaces are not wetted by water, presenting low surface energy. They are usually designed by two methods: i) applying surface treatments with lowsurface-energy, and ii) creating a rough surface [6]. The benefits of the promotion of this capability for the materials are diverse, providing functions such as waterresistant, anti-icing, antibacterial, contaminant-free, selfcleaning, and anticorrosive [5].

\section{Application Method}

Some nano/micromaterials (with a grain size between 6 $\mathrm{nm}$ and $45 \mu \mathrm{m}$ ) have been applied on asphalt mixtures: $\mathrm{TiO}_{2}$, ZnO [3], modified-SiO ${ }_{2}$ [7], modified fluorinecontaining polymer with nano-CaO [4], MagnesiumAluminium layered double hydroxides (Mg-Al LDHs) [2], and PTFE [1]. Usually, solutions (or dispersions) are prepared containing the nano/microparticles. They are applied by spraying over the asphalt mixture surfaces. In some cases, there is just one spraying process or even two. For the case of two spraying processes, the binder layer is applied, then the dispersed particles are sprayed over the binder layer [1,3].

* Corresponding author: iran gomes@hotmail.com 


\section{Analysis}

The superhydrophobic capability is mostly evaluated by optical and electron analysis. The main method is by measuring the CA of the water and the surface. As mentioned before, $\mathrm{CA}$ must be higher than $150^{\circ}$ to guarantee the superhydrophobic surface.

As previously described, the surface should be rough, being essential to the analysis of the microtopography of the surface. The surface roughness is usually analysed by optical methods, for example, by optical triangulation based-microtopography (Fig. 1). In this case, surface parameters can be assessed in order to characterize it and compare materials and treatments.

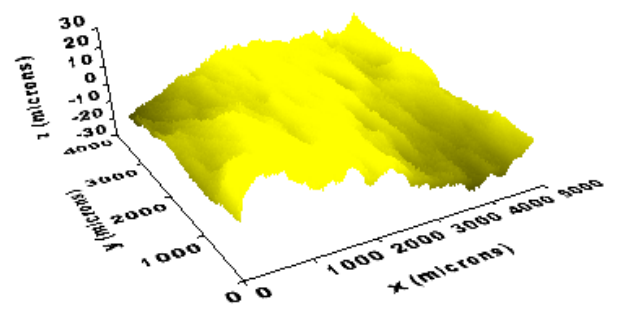

Fig.1. Microtopography of an asphalt mixture.

Also, the images by Scanning Electron Microscope (SEM) are essential to understand the microtopographic structure of the surface. In Fig. 2, the self-cleaning effect is showed by water drops carrying the dirt particles that were previously deposited, as the effect of the Lotus Flower [8]. A biomimetic approach is developed to provide a self-cleaning effect.

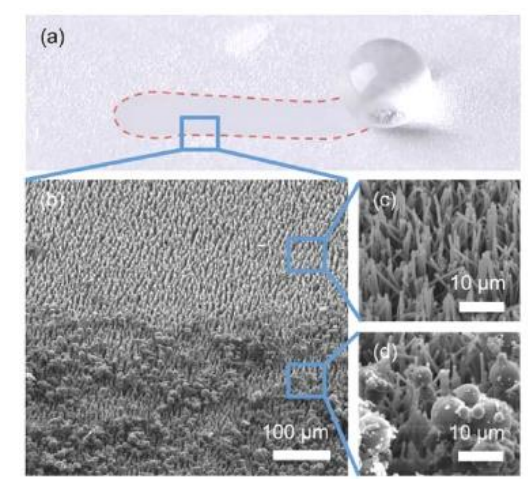

Fig. 2: a) Water drop carrying dirt. Adapted from [8].

Tests to check the feasibility are also conducted: friction $[1,9]$, water drop freezing [2], and durability $[2,4]$.

\section{Results on Literature}

Table 1 summarizes the main results in the literature. Most of the research work has used nanoparticles. The CA ranges from 150 to $166^{\circ}$, depending on the material and application method. The highest CA was achieved by using microparticles of PTFE [1]. The superhydrophobic asphalt mixtures can present rough surface $[2,4]$, delay water freezing [2,7], decreasing the ice adhesion force [2]. Besides, friction was slightly influenced by water and ice [9]. Durability should be further explored.
Table 1. Superhydrophobic Asphalt Mixtures.

\begin{tabular}{|c|c|c|c|c|}
\hline Material & $\begin{array}{c}\text { Grain } \\
\text { size } \\
(\mathbf{n m})\end{array}$ & $\begin{array}{c}\text { Dispersion } \\
\text { Medium }\end{array}$ & $\begin{array}{c}\text { CA } \\
\left({ }^{\circ}\right)\end{array}$ & Ref. \\
\hline $\mathrm{TiO}_{2}$ & $23-28$ & Water & 150 & {$[3]$} \\
\hline $\begin{array}{c}\text { Modified- } \\
\mathrm{SiO}_{2}\end{array}$ & 20 & $\begin{array}{c}\text { Silanes, } \\
\text { Water, } \\
\text { Ethanol, and } \\
\text { Ammonia }\end{array}$ & 151 & {$[7]$} \\
\hline $\mathrm{TiO}_{2} \mathrm{ZnO}$ & $\begin{array}{c}23-28, \\
45000\end{array}$ & Water & 155 & {$[3]$} \\
\hline $\mathrm{Mg}^{\mathrm{A} 1 \mathrm{LDHs}}$ & 100 & Naphtha & 152 & {$[2]$} \\
\hline$*$ & $*$ & $*$ & 157 & {$[9]$} \\
\hline $\begin{array}{c}\text { Fluorine } \\
\text { polymer with } \\
\text { nano-CaO }\end{array}$ & $6-20$ & Water & 163 & {$[4]$} \\
\hline PTFE & 12000 & Acetone** & 166 & {$[1]$} \\
\hline
\end{tabular}

*Not described by the authors

**One binder layer composed of epoxy resin dissolved in xylene was sprayed before the application of the particles.

\section{Conclusions}

Superhydrophobic coatings containing PTFE, $\mathrm{TiO}_{2}, \mathrm{TiO}_{2}$ and $\mathrm{ZnO}, \mathrm{SiO}_{2}, \mathrm{Mg}-\mathrm{Al} \mathrm{LDHs}$, and fluorine polymer with nano- $\mathrm{CaO}$ nano/microparticles have been applied over asphalt mixtures to improve safety. They are tested under optical and electron analysis (CA, surface roughness, and SEM images), friction, water drop freezing, and durability. Relevant literature results indicate that road can be safer with superhydrophobic asphalt mixtures.

\section{References}

1. A. Arabzadeh, H. Ceylan, S. Kim, K. Gopalakrishnan, A. Sassani, Transp Res Rec J Transp Res Board 2551, 10-17 (2016)

2. C. Peng, H. Zhang, Z. You, F. Xu, G. Jiang, S. Lv, R. Zhang, Constr Build Mater 189, 227-235 (2018)

3. I. Rocha Segundo, C. Ferreira, E.F. Freitas, J.O. Carneiro, F. Fernandes, S. Landi Júnior, M.F. Costa, Constr Build Mater 166, 36-44 (2018)

4. J.H.O. Nascimento, P. Pereira, E. Freitas, F Fernandes, 7th Int. Conf. Maint. Rehabil. Pavements Technol. Control, At Auckland, New Zealand (2012)

5. H. Zhu, Z. Guo, W. Liu, Chem Commun 50, 30, 3900-3913 (2014)

6. S. Heinonen, E. Huttunen-Saarivirta, J.P. Nikkanen, M. Raulio, O. Priha, J. Laakso, E. Storgårds, E. Levänen, Colloids Surfaces A: Physicochem Eng Asp 453,1, 149-161 (2014)

7. Y. Gao, L. Qu, B. He, K. Dai, Z. Fang, R. Zhu, Constr Build Mater 191, 270-280 (2018)

8. J. Lee, R.S. Fearing, Langmuir 28, 43, 15372-15377 (2012)

9. E. Eriskin, S. Karahancer, S. Terzi, M. Saltan, Procedia Eng 187, 532-7 (2017) 